\title{
A Historical Survey of Geometric Computer Vision
}

\author{
Peter Sturm \\ INRIA Grenoble Rhône-Alpes and Laboratoire Jean Kuntzmann, Grenoble, France \\ Peter.Sturm@inria.fr
}

\begin{abstract}
This short paper accompanies an invited lecture on a historical survey of geometric computer vision problems. It presents some early works on image-based 3D modeling, multi-view geometry, and structurefrom-motion, from the last three centuries. Some of these are relatively well known to photogrammetrists and computer vision researchers whereas others seem to have been largely forgotten or overlooked. This paper gives a very brief summary of an ongoing historical study.
\end{abstract}

Keywords: Geometry, photogrammetry, structure-from-motion, 3D modeling, history.

\section{3D Modeling from Perspectives}

Relatively quickly after the invention of photography in the 1830' 1 , the idea of using photographs for map creation and 3D modelling (terrains, buildings) emerged. Laussedat seems to have been the first to exploit photographs for topographic modelling [32; he is thus commonly considered as the father of photogrammetry. In the 1850's and 1860's, he developed and used an approach for topographic map generation, first with perspective drawings generated using the so-called camera lucida [30, later with actual photographs. The approach requires perspective images taken in particular conditions (horizontal optical axes, known distance between the viewpoints, known internal parameters) and carries out the mapping using elementary operations for the determination of the relative horizontal orientation of the perspectives, of planar point triangulation, and height measurement. The cameras were usually coupled with theodolites, providing accurate angle measurements.

It is noteworthy that essentially the same principles were used already before the existence of photography to generate topographic maps. Beautemps-Beaupré developed an approach to do so, from hand-drawn "perspectives" to which angles measured by theodolites, between sight lines to pairs of points, were added [2]. Here, the hand-drawn images seem mainly to have been used for documentation purposes as opposed to for actual measurements. This approach was used in marine expeditions as early as in the 1790's to acquire topographic maps of

\footnotetext{
${ }^{1}$ The invention of photography was the result of long-term efforts of many researchers
} in different countries, although the "official" birthdate is often given as 1837 or 1839 .

A. Berciano et al. (Eds.): CAIP 2011, LNCS 6854, pp. 1-8 2011.

(C) Springer-Verlag Berlin Heidelberg 2011 
foreign coastlines, from observations made on board of ships and where possible, combining these with land-based measurements.

An even earlier example of 3D modeling aided by drawings may be due to Kappeler 2 , who produced in 1726 a topographic map of a mountain range in Switzerland, Mount Pilatus 2413]. Although Kappeler stated that he used perspective drawings, no details on the approach are given, which is why in photogrammetric litterature this work is usually not considered as the first undisputable example of $3 \mathrm{D}$ modeling using inverse perspective methods.

\section{2 "Hardware"}

The maturation of photogrammetry was made possible by theoretical developments, as well as, if not more, by practical inventions. The latter concerned of course photographic equipment as such, but also devices that ease the use of cameras for measurement purposes, such as combinations of cameras and theodolites. While such "hardware developments" are not the central issue of this paper, we still like to mention that concepts such as panoramic image acquisition and multi-camera systems, were developed relatively early. Indeed, it was soon recognized that panoramic images may ease photogrammetric work; the first panoramic camera may be one developed by Puchberger in 1843, i.e. just a few years after the invention of modern photography [35]. Multi-camera systems were developed at least as early as in 1884, initially mainly if not exclusively for aerial imaging. The earliest work known to me (no effort was made for an exhaustive bibliography research) is that of Triboulet, who, as reported in [45] experimented from 1884 on with a multi-camera system consisting of 7 cameras attached to a balloon: one camera looked downwards and 6 cameras were equally distributed around the balloon's circumference (the system thus resembles the popular Ladybug sensor). In addition to hardware for the acquisition of images and complementary measurements, photogrammetry progressed signficantly through the development of equipment and procedures to exploit the acquired images, see e.g. an early survey in $31 \mid 33$.

\section{Epipolar and Multi-view Geometry}

Epipolar geometry seems to have been first uncovered by Hauck in 1883 [17. In the same paper as well as follow-up papers [18|19|20|21, trilinear relationships of points and lines seen in three images, were also described. In his work, Hauck did not deeply analyze these trilinear relationships theoretically, like was done via trifocal tensors in the 1990's; he rather concentrated on the application of these relationships to generate a third image from two given ones (often called "trifocal transfer" in computer vision).

Previously, in 1863, Hesse proposed an algebraic solution to an exercise proposed by Chasles in 3]: given seven pairs of matching $2 \mathrm{D}$ points, the goal is to

\footnotetext{
${ }^{2}$ Often spelled Cappeler.
} 
determine two pencils of 2D lines in homographical relation such that matching lines are incident with matching points. Further, Chasles asked to prove that there exist only three solutions to this problem. Hesse proposed a solution to this problem that is effectively equivalent to the 7-point method for computing the fundamental matrix, or epipolar geometry, between two perspective images of a rigid $3 \mathrm{D}$ object [22], although the link to epipolar geometry only became clear later.

Before Hesse, de Jonquières gave a geometrical solution and proof for Chasles' problem [7, which were later slightly clarified by Cremona [4]. Sturm studied the same problem as well as generalizations to other numbers of points, from a theoretical viewpoint 41 .

The special case of six point matches for which it is known that four arise from coplanar points in the scene, was solved by Finsterwalder in 1899 [10].

\section{Projective Reconstruction}

Hauck, in the above works, already touches upon the issue of projective reconstruction [17]18]19|20|21]. In 1899, Finsterwalder gives a clear exposition of the fact that from a set of uncalibrated images, a projective 3D reconstruction is possible and provides an algorithm for the case of two images 10 . The concept of projective reconstruction was re-discovered in computer vision in the early 1990's 916.

\section{Self-calibration}

In the same article where he explained the feasibility of projective reconstruction, Finsterwalder also showed that self-calibration from images of an unknown rigid object is possible [10. He proposed a geometric construction based on the absolute conic and the circular points of image planes, didn't find an analytical solution though. In computer vision, self-calibration was first formulated for the case of images acquired by a camera with fixed intrinsic parameters [34 and then extended towards images acquired with different intrinsics [23]38. Finsterwalder directly considered the problem of images with possibly different intrincis; he showed that with four images taken with possibly varying focal length and principal point, a finite number of solutions exists.

His construction goes as follows (formulated in computer vision jargon, the original explanations being somewhat different). Given a projective reconstruction of the object and the cameras. Under the assumption of square pixels, the image of the absolute conic is a circle, hence it contains the two circular points of the image plane. Let us now back-project the circular points to 3D lines in the projective reconstruction; these must intersect the absolute conic. For four images, we thus get eight 3D lines that intersect the absolute conic. This is in general sufficient to determine (a finite number of solutions for) the plane at infinity ( 3 degrees of freedom) and the absolute conic lying on it ( 5 degrees of freedom). Hence, the self-calibration problem can in general be solved. 
Self-calibration from rotations. The possibility of determining the focal length from images acquired by rotating a camera, was mentioned by Meydenbauer in 1892 [36]. In [46, von Gruber described topographic and photogrammetric acquisitions made during an expedition in the Pamir mountain range in 1913 and subsequent measurements and the generation of a map. Panoramic image acquisition by rotating the camera about its optical center, was an integral part of the procedures used. It is mentioned that this was also used to determine the focal length of cameras.

The above approaches deal with the case of known principal point and "only" determine the focal length 42. This was generalized in 1939 by Sutor to the determination of both, the focal length and the principal point, as well as radial distortion, from a set of images spanning a full circle 42. His method, like the others above, assumes that the camera rotates about either the horizontal or vertical axis of its coordinate system (errors resulting from deviations from this setup are investigated by Sutor and shown to be negligible in practice). Thus, only the horizontal or vertical coordinate of the principal point is considered respectively computed. Sutor's method is iterative, starting from initial values. Besides providing details of the method, Sutor also gave a theoretical error analysis.

Wester-Ebbinghaus extended this approach towards using images acquired in arbitrary orientations around the fixed optical center and without requiring a closed image sequence [48. Like Sutor, he did not propose "closed-form" solutions and solved the problem in a bundle adjustment manner. He also proposed a bundle adjustment formulation for the case where a camera rotates about a fixed point different from the optical center.

General closed-form solutions were developed by Hartley et al. [15]6].

(Self-) calibration from 3 orthogonal vanishing points. This is a simple (in general inaccurate) calibration idea which only requires one image of a rectangular parallelepiped and the extraction of the 3 vanishing points associated with its edges. Such an image allows to compute the camera's focal length and principal point (if the object is in general position). This idea was discovered independently by many researchers over time, starting with the famous mathematician Taylor in 1715 [43. Later references include [10[118|1].

\section{Orientation Procedures - Structure-from-Motion}

The main building blocks for structure-from-motion algorithms are what is called orientation procedures in photogrammetry: pose estimation (space resection), motion estimation (relative orientation), and 3D point triangulation (intersection). These are classical problems, see e.g. the excellent overview [49]. A few notes on pose and motion estimation, follow.

Pose estimation. Taylor and Lambert were probably among the first to have posed "inverse perspective problems" in a general manner [43/44|29], both in the 18th century. Lambert (who also studied shading and developed the so-called 
Lambertian reflectance model), proposed and solved a series of such problems, including pose estimation, estimation of the focal length, and of the orientation of an image. This was mostly restricted to special cases, for instance the assumption of an image plane that is orthogonal to a ground plane and the existence of rectangles or squares on the ground plane 29. Interestingly, Lambert's studies were partly motivated by aesthetic considerations: his premise was that in order to best contemplate a (perspective) painting, the observer should put himself in a position relative to the painting that corresponds to the painter's eyepoint relative to the depicted scene. His initial goal thus seems to have been the determination of this "pose" from information contained in the painting (e.g. vanishing points) and additional knowledge.

Maybe the first analytical solution to the so-called 3-point pose problem, was found by Lagrange: determine the position and orientation of a "camera" (Lagrange obviously didn't speak of cameras) relative to three 3D points, given knowledge of the relative positions of these points and the angles spanned by pairs of points and the optical center. Lagrange discussed this problem at least as early as from 1773 on $27 / 28$. He already showed that it can be reduced to finding the roots of a quartic polynomial and also sketches an iterative numerical procedure. He very likely had the complete solution although the above publications only give a general sketch and do not contain all details.

A complete analytical solution was eventually given by Grunert in 1841 [12]. Many other solutions have been proposed in the literature since, see e.g. the survey [14.

Motion estimation. Kruppa showed in 1913 that from five point matches between two calibrated images of a rigid object, the relative pose between the images can be computed up to a finite number of solutios [26]. Later works on the 5-point problem are 37] and references therein.

The special case of a planar object was already solved by Schröter in 1880 (paragraph 45 of 39). He showed how from two calibrated images of four coplanar points, these points as well as the camera positions and orientations, can be computed up to two solutions. An equivalent result was given later by Kruppa (section A of [25]).

\section{Special Cases of 3D Modeling}

Shape from silhouettes. Amazingly, this was one of the first 3D modeling approaches to be developed: around 1857, François Willème developed an approach, baptized photo-sculpture (see e.g. [47]), that is nothing else than a "mechanical" version of shape from silhouettes or, the visual hull. Willème acquired images in a circle around an object (usually, a person). These were then projected to a screen, one after the other; behind the screen, a block of clay or other material easy to sculpt, was positioned on a turntable, which was rotated in order to reproduce the current image's orientation while it was acquired. Then, using a so-called pantograph (an articulated instrument), the sculptor followed the silhouettes of the object on the projector screen, while steering a bar that carved 
away the parts of the clay block that lie outside the silhouette. By repeating this procedure for all images, the outcome is nothing else than the object's visual hull in clay! This was finally worked on by an actual sculptor, to round edges and add details, in order to produce a visually pleasing statue. Interestingly, this concept seems to have been very popular in high society circles for several years, and Willème created what one might nowadays call a start-up company, commercializing this concept (he was even imitated in other countries).

Single-view 3D modeling. The idea of performing 3D modeling from a single image of an object, was proposed by several researchers in the late 19th century [17/1036/32]. Like their modern counterparts, see e.g. [5/40], the proposed approaches relied on the exploitation of geometric constraints provided by the user, such as parallelism of lines, right angles, etc.

\section{Conclusion}

As mentioned in the abstract, this paper is the result of a historical study that is in progress. In the mid-term future, it will be complemented by a more complete treatment, containing more technical details, (many) more references, and covering other aspects such as 3D modeling from shadows, structure-from-motion for refractive objects (also called "multimedia-photogrammetry"), structured lighting, 3D modeling of surfaces of revolution, etc.

Acknowledgement. I am grateful to the Alexander-von-Humboldt Foundation for a Research Fellowship supporting a sabbatical at TU Munich, during which the literature search underpinning this survey was mainly carried out.

\section{References}

1. Caprile, B., Torre, V.: Using Vanishing Points for Camera Calibration. IJCV 4, 127-140 (1990)

2. Chapuis, O.: À la mer comme au ciel - Beautemps-Beaupré et la naissance de l'hydrographie moderne (1700-1850). Presse de l'Université de Paris-Sorbonne (1999)

3. Chasles, M.: Question 296. Nouvelles annales de Mathématiques 1(14), 50 (1855)

4. Cremona, M.: Sur un problème d'homographie (question 296). Nouvelles annales de Mathématiques 1(20), 452-456 (1861)

5. Criminisi, A.: Accurate Visual Metrology from Single and Multiple Uncalibrated Images. PhD thesis, University of Oxford (1999)

6. de Agapito, L., Hayman, E., Hartley, R.I.: Linear self-calibration of a rotating and zooming camera. In: CVPR, pp. 1015-1021 (1999)

7. de Jonquières, M.: Solution géométrique de la question 296. Nouvelles annales de Mathématiques 1(17), 399-403 (1858)

8. Echigo, T.: A camera calibration technique using three sets of parallel lines. Machine Vision and Applications 3(3), 159-167 (1990)

9. Faugeras, O.: What can be seen in three dimensions with an uncalibrated stereo rig? In: Sandini, G. (ed.) ECCV 1992. LNCS, vol. 588, pp. 563-578. Springer, Heidelberg (1992) 
10. Finsterwalder, S.: Die geometrischen Grundlagen der Photogrammetrie. Jahresbericht Deutscher Mathematik 6, 1-44 (1899)

11. Gracie, G.: Analytical photogrammetry applied to single terrestrial photograph mensuration. In: XIth International Congress of Photogrammetry (1968)

12. Grunert, J.A.: Das pothenot'sche Problem in erweiterter Gestalt; nebst Bemerkungen über seine Anwendung in der Geodäsie. Archiv der Mathematik und Physik, 238-248 (1841)

13. Günther, L.W.: Die erste praktische Anwendung des Meßbildverfahrens durch den Schweizer M.A. Cappeler im Jahre 1725. International Archives of Photogrammetry 3(4), 289-290 (1913)

14. Haralick, R.M., Lee, C., Ottenberg, K., Nölle, M.: Analysis and solutions of the three point perspective pose estimation problem. In: CVPR, pp. 592-598 (1991)

15. Hartley, R.I.: An algorithm for self calibration from several views. In: CVPR, pp. 908-912 (1994)

16. Hartley, R.I., Gupta, R., Chang, T.: Stereo from uncalibrated cameras. In: CVPR, pp. 761-764 (1992)

17. Hauck, G.: Neue Constructionen der Perspective und Photogrammetrie (Theorie der trilinearen Verwandtschaft ebener Systeme) - 1st article. Journal für die reine und angewandte Mathematik 95(1), 1-35 (1883)

18. Hauck, G.: Theorie der trilinearen Verwandtschaft ebener Systeme. die orientirte Lage - 2nd article. Journal für die reine und angewandte Mathematik 97(4), 261276 (1884)

19. Hauck, G.: Theorie der trilinearen Verwandtschaft ebener Systeme. die dreibündigeindeutige Verwandtschaft zwischen drei ebenen Punktsystemen und ihre Beziehungen zur quadratischen und zur projectiv-trilinearen Verwandtschaft - 3rd article. Journal für die reine und angewandte Mathematik 98(4), 304-332 (1885)

20. Hauck, G.: Theorie der trilinearen Verwandtschaft ebener Systeme. die trilineare Beziehung zwischen drei einstufigen Grundgebilden - 4th article. Journal für die reine und angewandte Mathematik 108(1), 25-49 (1891)

21. Hauck, G.: Theorie der trilinearen Verwandtschaft ebener Systeme. zusammenfassung und wichtige Specialfälle - 5th article. Journal für die reine und angewandte Mathematik 111(3), 207-233 (1893)

22. Hesse, O.: Die cubische Gleichung, von welcher die Lösung des Problems der Homographie von M. Chasles abhängt. Journal für die reine und angewandte Mathematik 62, 188-192 (1863)

23. Heyden, A., Åström, K.: Euclidean reconstruction from image sequences with varying and unknown focal length and principal point. In: CVPR, pp. 438-443 (1997)

24. Kappeler, M.A.: Pilati Montis Historia. In: Imhof, J.R., Filii (eds.) Pago Lucernensi Helvetiae Siti, Figuris Aeneis Illustrata, Basel, Switzerland (1767)

25. Kruppa, E.: Über einige Orientierungsprobleme der Photogrammetrie. Sitzungsberichte der mathematisch-naturwissenschaftlichen Klasse der kaiserlichen Akademie der Wissenschaften, Abteilung II a 121(1), 3-16 (1912)

26. Kruppa, E.: Zur Ermittlung eines Objektes aus zwei Perspektiven mit innerer Orientierung. Sitzungsberichte der mathematisch-naturwissenschaftlichen Klasse der kaiserlichen Akademie der Wissenschaften, Abteilung II a 122(10), 1939-1948 (1913)

27. Lagrange, J.-L.: Solutions analytiques de quelques problèmes sur les pyramides triangulaires (1773); reprinted in 1869 in the 3rd volume of the Cuvres de Lagrange edited by J.-A. Serret and published by Gauthier-Villars 
28. Lagrange, J.-L.: Leçons élémentaires sur les mathématiques données à l'École Normale en (1795); 1795, reprinted in 1877 in the 7th volume of the CEuvres de Lagrange, edited by J.-A. Serret and published by Gauthier-Villars

29. Lambert, J.H.: Die freye Perspektive, oder Anweisung, jeden perspektivischen Aufriß von freyen Stücken und ohne Grundriß zu verfertigen. Heidegger und Compagnie, Zurich (1759)

30. Laussedat, A.: Mémoire sur l'emploi de la chambre claire dans les reconnaissances topographiques, Mallet-Bachelier, Paris. Mémorial du Génie, vol. 16 (1854)

31. Laussedat, A.: Recherches sur les instruments, les méthodes et le dessin topographiques, vol. 1. Gauthier-Villars, Paris (1898)

32. Laussedat, A.: La métrophotographie. Gauthier-Villars, Paris (1899)

33. Laussedat, A.: Recherches sur les instruments, les méthodes et le dessin topographiques, vol. 2. Gauthier-Villars, Paris (1901)

34. Maybank, S.J., Faugeras, O.D.: A theory of self calibration of a moving camera. IJCV 8(2), 123-151 (1992)

35. McBride, B.: A timeline of panoramic cameras, http://www . panoramicphoto.com/timeline.htm?

36. Meydenbauer, A.: Das photographische Aufnehmen zu wissenschaftlichen Zwecken, insbesondere das Messbild-Verfahren - Erster Band: Die photographischen Grundlagen und das Messbild-Verfahren mit kleinen Instrumenten. Unte's VerlagsAnstalt, Berlin (1892)

37. Nistér, D.: An efficient solution to the five-point relative pose problem. IEEETPAMI 26(6), 756-770 (2004)

38. Pollefeys, M., Koch, R., Van Gool, L.: Self-calibration and metric reconstruction in spite of varying and unknown internal camera parameters. In: ICCV, pp. 90-95 (1998)

39. Schröter, H.: Theorie der Oberflächen zweiter Ordnung und der Raumkurven dritter Ordnung als Erzeugnisse projektivisher Gebilde. In: Nach Jacob Steiner's Prinzipien auf synthetischem Wege abgeleitet. B.G. Teubner, Leipzig (1880)

40. Sturm, P., Maybank, S.J.: A method for interactive 3D reconstruction of piecewise planar objects from single images. BMVC, 265-274 (1999)

41. Sturm, R.: Das Problem der Projektivität und seine Anwendung auf die Flächen zweiten Grades. Mathematische Annalen 1, 533-574 (1869)

42. Sutor, J.: Bestimmung der inneren Orientierung und Verbildung aus Rundbildern. PhD thesis, Technische Hochschule Berlin (1939)

43. Taylor, B.: Linear perspective: or, a new method of representing justly all manner of objects as they appear to the eye in all situations (1715)

44. Taylor, B.: New principles of linear perspective: or the art of designing on a plane the representations of all sorts of objects, in a more general and simple method than has been done before (1719)

45. Tissandier, G.: La photographie en ballon. Gauthier-Villars (1886)

46. von Gruber, O.: Topographische Ergebnisse der Pamir-Expedition des D. u. ö (Deutschen und österreichischen) Alpenvereines 1913. International Archives of Photogrammetry 6, 156-181 (1923)

47. Wells, D.A.: Photo-sculpture. Annual of Scientific Discovery: Or, Year-Book of Facts in Science, 183-185 (1865)

48. Wester-Ebbinghaus, W.: Einzelstandpunkt-Selbstkalibrierung - ein Beitrag zur Feldkalibrierung von Aufnahmekammern, Habilitation thesis (1982)

49. Wrobel, B.: Minimum solutions for orientation. In: Gruen, A., Huang, T.S. (eds.) Calibration and Orientation of Cameras in Computer Vision. Springer, Heidelberg (2001) 